The Astrophysical Journal, 185:L67-L70, 1973 October 15

(C) 1973. The American Astronomical Society. All rights reserved. Printed in U.S.A.

\title{
CARBON MONOXIDE EMISSION FROM NEBULOSITY ASSOCIATED WITH HERBIG Be AND Ae TYPE STARS
}

\author{
R. B. Loren, P. A. Vanden Bout, and J. H. Davis \\ University of Texas at Austin \\ Received 1973 July 20
}

\begin{abstract}
Carbon monoxide emission in both the ${ }^{12} \mathrm{C}^{16} \mathrm{O}$ and ${ }^{13} \mathrm{C}^{16} \mathrm{O} J=1-0$ lines has been observed from the regions near all the $\mathrm{Be}$ and Ae stars associated with nebulosity listed by Herbig. The emission intensity is peaked on the position of the star in all but a few cases.
\end{abstract}

Subject headings: molecules, interstellar - pre-main-sequence stars - radio lines - star formation

\section{INTRODUCTION}

According to models of star formation proposed by Larson (1969) an interstellar cloud collapses nonhomologously to form a central protostar surrounded by a still collapsing protostellar nebula. These models predict a close association between very young stellar systems and the nebulosity in which they are found. This is particularly true of the more massive systems $\left(M \sim 3 M_{\odot}\right)$ which can evolve as far as the main sequence before the protostellar nebula can be accreted. As part of a program studying the molecular line emission from dense interstellar clouds, we have searched for carbon monoxide $(J=1-0)$ emission from the regions surrounding all the $\mathrm{Be}$ and Ae stars listed by Herbig (1960) as potentially being the more massive analogs of the $T$ Tauri stars. The extreme youth of these stars has been established by Strom et al. (1972).

\section{OBSERVATIONS}

The observations were made with the 16-foot $(5-\mathrm{m})$ millimeter antenna of the Millimeter Wave Observatory, Fort Davis, Texas. ${ }^{1}$ A cooperative program of research combines this antenna with a millimeter spectral line receiver developed at Bell Telephone Laboratories and a set of filters, integrators, and data-handling equipment from the Harvard College Observatory radio group. The observations reported here were made in 1973 January, March, and June. Forty frequency channels of width and spacing equal to $250 \mathrm{kHz}$ were used. This corresponds to a velocity resolution of $0.65 \mathrm{~km} \mathrm{~s}^{-1}$ for the ${ }^{12} \mathrm{C}^{16} \mathrm{O}$ line. The beam resolution was $2 ! 6$. The thermal scale was established by synchronously detecting an ambient temperature absorber on a chopper wheel which could be rotated in front of the feed horn (Penzias and Burrus 1973). Corrections for atmospheric extinction have been made following Davis and Vanden Bout (1973). The quantity used here to report line intensities is $\eta_{p} T_{B}$ where $T_{B}$ is the brightness temperature in the usual sense (referred outside the Earth's atmosphere) and $\eta_{p}$ is the fraction of the forward beam that falls on the source.

Herbig's original list contains 26 stars. In two cases there are two of these stars associated with the same interstellar cloud. We did not observe $\mathrm{T}$ Ori located in the Orion Nebula or $\mathrm{LkH}_{\alpha} 25$ located in NGC 2264, as the carbon monoxide emission of these clouds has been studied previously (Wilson, Jefferts, and Penzias 1970; Liszt 1973 ). In table 1 we list the 22 remaining Herbig objects, the name of the associated

1 The Millimeter Wave Observatory is operated by the Electrical Engineering Research Laboratory, University of Texas at Austin, with support from the National Aeronautics and Space Administration, the National Science Foundation, and McDonald Observatory. 
TABLE 1

\begin{tabular}{|c|c|c|c|c|c|c|}
\hline \multirow{2}{*}{$\begin{array}{l}\text { HERBIG } \\
\text { StAR* }\end{array}$} & \multirow{2}{*}{$\begin{array}{l}\text { Associated } \\
\text { Cloud }\end{array}$} & \multicolumn{2}{|c|}{${ }^{12} \mathrm{C}^{18} \mathrm{O}$} & \multicolumn{2}{|c|}{${ }^{13} \mathrm{C}^{100}$} & \multirow{2}{*}{$\frac{{ }^{12} \mathrm{C}^{16} \mathrm{O} \dagger}{V_{\mathrm{LSR}}\left(\mathrm{km} \mathrm{s}^{-1}\right)}$} \\
\hline & & $\eta_{p} T_{B}\left({ }^{\circ} \mathrm{K}\right)$ & $\Delta V\left(\mathrm{~km} \mathrm{~s}^{-1}\right)$ & $\eta_{p} T_{B}\left({ }^{\circ} \mathrm{K}\right)$ & $\Delta V\left(\mathrm{~km} \mathrm{~s}^{-1}\right)$ & \\
\hline $\begin{array}{l}\mathrm{LkH} \alpha 198 \ldots \ldots \ldots \ldots \\
\mathrm{BD}+61^{\circ} 154 \ldots \ldots \ldots \ldots \\
\mathrm{AB} \text { Aur } \ldots \ldots \ldots \ldots \ldots\end{array}$ & $\mathrm{L} 1517$ & $\begin{array}{r}13.9 \\
5.6 \\
11.8\end{array}$ & $\begin{array}{l}2.8 \\
2.0 \\
1.2\end{array}$ & $\begin{array}{l}2.8 \\
0.5 \\
2.9\end{array}$ & $\begin{array}{l}1.7 \\
2.0 \\
1.0\end{array}$ & $\begin{array}{l}+\quad 0.3 \\
+\quad 3.2 \\
+\quad 6.0\end{array}$ \\
\hline $\begin{array}{l}\text { HK Ori } \ldots \ldots \ldots \ldots \ldots \\
\text { V380 Ori } \ldots \ldots \ldots \ldots \ldots \\
\text { RR Tau } \ldots \ldots \ldots \ldots\end{array}$ & NGC 1999 & $\begin{array}{l}20.9 \\
22.2 \\
12.3\end{array}$ & $\begin{array}{l}1.3 \\
3.5+ \\
1.8\end{array}$ & $\begin{array}{l}7.8 \\
8.3 \\
2.2\end{array}$ & $\begin{array}{l}1.3 \\
1.2\end{array}$ & $\begin{array}{r}+10.6 \\
+\quad 8.9 \\
-\quad 5.4\end{array}$ \\
\hline $\begin{array}{l}\mathrm{HD} 250550 \ldots \ldots \ldots \ldots \\
\mathrm{LkH} \alpha 208 \ldots \ldots \ldots \ldots \\
\mathrm{LkH} \alpha 215 \ldots \ldots \ldots \ldots\end{array}$ & NGC 2245 & $\begin{array}{r}7.2 \\
8.7 \\
13.8\end{array}$ & $\begin{array}{l}2.4 \\
1.8 \\
2.7\end{array}$ & $\begin{array}{l}2.9 \\
1.6 \\
3.8\end{array}$ & $\begin{array}{l}0.8 \\
1.3 \\
1.1\end{array}$ & $\begin{array}{l}+\quad 2.4 \\
+\quad 0.2 \\
+\quad 2.9\end{array}$ \\
\hline $\begin{array}{l}\text { HD } 259431 \ldots \ldots \ldots \ldots \\
\text { R Mon } \ldots \ldots \ldots \ldots \ldots \ldots \\
\text { Z CMa } \ldots \ldots \ldots \ldots \ldots\end{array}$ & $\begin{array}{l}\text { NGC } 2247 \\
\text { NGC } 2261\end{array}$ & $\begin{array}{l}15.9 \\
10.0 \\
12.5\end{array}$ & $\begin{array}{l}2.3 \\
1.8 \\
2.0\end{array}$ & $\begin{array}{l}2.8 \\
1.0 \\
3.2\end{array}$ & $\begin{array}{l}1.7 \\
1.0 \\
1.8\end{array}$ & $\begin{array}{r}+4.8 \\
+\quad 9.4 \\
+13.6\end{array}$ \\
\hline $\begin{array}{l}\text { HD } 53367 \ldots \ldots \ldots \\
\text { MWC } 297 \ldots \ldots \\
\text { R CrA and } \mathrm{T} \text { CrA } \ldots \ldots\end{array}$ & $\begin{array}{l}\text { IC } 2177 \\
\text { NGC } 6729\end{array}$ & $\begin{array}{r}15.4 \\
3.7 \\
22.5\end{array}$ & $\begin{array}{c}3.5 \\
11.0 \S \\
3.8\end{array}$ & $\begin{array}{r}4.4 \\
2.9 \\
12.2\end{array}$ & $\begin{array}{l}2.3 \\
3.0 \\
1.8\end{array}$ & $\begin{array}{l}+17.9 \\
+\quad 5.7 \S \\
+\quad 5.5\end{array}$ \\
\hline $\begin{array}{l}\mathrm{BD}+40^{\circ} 4124 \ldots \ldots \ldots \\
\mathrm{BD}+41^{\circ} 3731 \ldots \ldots \ldots \ldots \\
\mathrm{HD} 200775 \ldots \ldots \ldots \ldots\end{array}$ & $\begin{array}{l}\text { NGC } 6914 b \\
\text { NGC } 7023\end{array}$ & $\begin{array}{l}24.6 \\
20.7 \\
12.8\end{array}$ & $\begin{array}{l}2.5 \\
2.6 \\
3.4\end{array}$ & $\begin{array}{l}7.3 \\
8.5 \\
4.5\end{array}$ & $\begin{array}{l}1.5 \\
2.2 \\
1.8\end{array}$ & $\begin{array}{l}+\quad 7.8 \\
+\quad 5.1 \\
+\quad 1.0\end{array}$ \\
\hline $\begin{array}{l}\mathrm{BD}+65^{\circ} 1637 \\
\quad \text { and } \mathrm{LkH} \alpha 234 \ldots \ldots \ldots \\
\mathrm{BD}+46^{\circ} 3471 \ldots \ldots \ldots \ldots \\
\mathrm{LkH} \alpha \quad 233 \ldots \ldots \ldots \ldots\end{array}$ & $\begin{array}{l}\text { NGC } 7129 \\
\text { IC } 5146\end{array}$ & $\begin{array}{l}18.0 \\
10.2 \\
15.7\end{array}$ & $\begin{array}{l}2.8 \\
1.9 \\
1.6\end{array}$ & $\begin{array}{l}8.2 \\
3.2 \\
5.5\end{array}$ & $\begin{array}{l}2.0 \\
1.7 \\
1.5\end{array}$ & $\begin{array}{r}-10.0 \\
+\quad 6.5 \\
0.0\end{array}$ \\
\hline MWC $1080 \ldots \ldots \ldots$ & & 7.9 & 4.1 & 2.3 & 3.2 & -29.3 \\
\hline
\end{tabular}

* The coordinates of the observed positions are those given by Herbig (1960) for the objects listed here, except: $\mathrm{LkH} \alpha$ 198, $\alpha=0^{\mathrm{h}} 8^{\mathrm{m}} 43.6^{\mathrm{s}}, \delta=+58^{\circ} 33^{\prime} 08^{\prime \prime} ; \mathrm{LkH} \alpha 208, \alpha=6^{\mathrm{h}} 4^{\mathrm{m}} 54.4^{\mathrm{s}}, \delta=+18^{\circ} 39^{\prime} 54^{\prime \prime}$; $\mathrm{Z} \mathrm{CMa}, \alpha=07^{\mathrm{h}} 01^{\mathrm{m}} 22.6^{\mathrm{s}}, \delta=-11^{\circ} 28^{\prime} 36^{\prime \prime} ;$ MWC $297, \alpha=18^{\mathrm{h}} 25^{\mathrm{m}} 00.4^{\mathrm{s}}, \delta=-3^{\circ} 51^{\prime} 59^{\prime \prime} ; \mathrm{BD}^{\circ}+65^{\circ}$ $1637, \alpha=21^{\mathrm{h}} 41^{\mathrm{m}} 54.9^{\mathrm{s}}, \delta=65^{\circ} 52^{\prime} 55^{\prime \prime}$; and MWC $1080, \alpha=23^{\mathrm{h}} 15^{\mathrm{m}} 11.5^{\mathrm{s}}, \delta=+60^{\circ} 34^{\prime} 24^{\prime \prime}$ (all for the epoch 1950).

$\dagger$ The ${ }^{13} \mathrm{C}^{16} \mathrm{O}$ lines appear at approximately the same radial velocity at the ${ }^{12} \mathrm{C}^{16} \mathrm{O}$ lines.

$\$$ The ${ }^{12} \mathrm{C}^{16} \mathrm{O}$ profile for V380 Ori consists of two overlapping components which resolve to 6.9 and $8.8 \mathrm{~km} \mathrm{~s}^{-1}$ in the ${ }^{13} \mathrm{C}^{16} \mathrm{O}$ line.

$\S$ The ${ }^{12} \mathrm{C}^{16} \mathrm{O}$ line has a broad flat-topped profile; the much narrower ${ }^{13} \mathrm{C}^{16} \mathrm{O}$ profile appears at the radial velocity given in the last column.

nebulosity, the strengths and widths of both the ${ }^{12} \mathrm{C}^{16} \mathrm{O}$ and ${ }^{13} \mathrm{C}^{16} \mathrm{O}$ lines, and the velocity (LSR) of the ${ }^{12} \mathrm{C}^{16} \mathrm{O}$ line.

We have made simple intensity maps for all the sources but the three weakest $\left(\mathrm{BD}+61^{\circ} 154, \mathrm{MWC} 297, \mathrm{MWC} 1080\right)$. In all but one case the peak line intensity of both isotopic species falls at or within one beamwidth of the stellar position. The sole exception is $\mathrm{BD}+46^{\circ} 3471$ which lies to the east of IC 5146 . Here the line intensity falls off uniformly from a peak of IC 5146 through the position BD $+46^{\circ} 3471$.

The extent of the $\mathrm{CO}$ emission is often small. In the extreme case of $\mathrm{R}$ Mon it is found only within one beamwidth of the star and is not detectable $\left(\eta_{p} T_{B} \leqslant 1^{\circ} \mathrm{K}\right)$ beyond these points. On the other hand, V380 Ori and R CrA have emission extending over a region of several square degrees. Detailed maps of these regions are being made and will be published later.

The mapping we have done thus far reveals quite different behavior of the carbon monoxide line strength with respect to optical indicators of dust and nebulosity. In 
HK Ori a strong line is formed in the vicinity of the star which falls to a much weaker line found in the surrounding dark cloud. The ${ }^{12} \mathrm{C}^{16} \mathrm{O}$ emission has a sharp boundary at the optical edge of the cloud. This is illustrated in figure $1 a$ (plate L7), where ${ }^{12} \mathrm{C}^{16} \mathrm{O}$ line strength $\left(\eta_{p} T_{B}\right)$ has been superimposed on an enlargement of the region taken from the Palomar Sky Survey. The opposite behavior can be seen in figure $1 b$, a similar illustration for AB Aur. Again, the line strength is peaked on the star and falls off with increasing distance, but there is no evidence of any correlation of line strength with the extinction which indicates dust clouds to the north and west of the star.

Another notable feature of the data is the narrowness of the lines, often less than $2 \mathrm{~km} \mathrm{~s}^{-1}$, indicating low turbulence in these clouds. Finally, there are often several velocity components. These are sometimes clearly resolved (AB Aur, RR Tau, Z CMa, $\left.\mathrm{BD}+40^{\circ} 4124, \mathrm{BD}+41^{\circ} 3731\right)$, although in other sources the components are barely resolved or indicated only by an asymmetric line profile (V380 Ori, MWC 297, HD 200775, and MWC 1080).

\section{DISCUSSION}

The detection of carbon monoxide emission near all of the very young stars making up this list and the coincidence of the position of peak line intensity with the position of the star establishes the close association between interstellar molecular clouds and the process of star formation which has been strongly indicated by earlier studies of molecular clouds. These results have prompted us to search other regions known to contain emission-line stars. Strong extended CO emission has been found in NGC 2068 and from the region near $\mathrm{LkH} \alpha 270$; more localized $\mathrm{CO}$ emission has been found near $\mathrm{LkH}_{\alpha} 101$ and FU Ori. The present data do not allow a detailed description of the nature of this association; an analysis of these clouds from observations of the lines of several molecules is required. We are searching for other molecules in these sources, and preliminary observations have yielded detections of CS and SO in NGC 7129 and SO in NGC 6726 near R CrA.

Radial velocities of the clouds are easily derived from the observed line frequencies. However, the line intensities have no similarly simple interpretation. A central problem is how the $\mathrm{CO}$ line temperatures are to be used to derive physical parameters describing the clouds. Previous analyses (e.g., Solomon 1973) have involved a number of assumptions-among them, that the beam was uniformly filled by the source $\left(\eta_{p}=1\right)$, that the ${ }^{13} \mathrm{C}^{16} \mathrm{O}$ line was unsaturated, and that the ${ }^{12} \mathrm{C} /{ }^{13} \mathrm{C}$ abundance ratio was the terrestrial value of 89 . Such an analysis immediately leads to large values of $\tau\left({ }^{12} \mathrm{C}^{16} \mathrm{O}\right)$ on the order of $\tau \sim 10-60$. With this high opacity we find it surprising that all of our ${ }^{12} \mathrm{C}^{16} \mathrm{O}$ line intensity maps have a peak close to or coincident with the position of the star. One would expect to see deeply into the cloud with the ${ }^{13} \mathrm{C}^{16} \mathrm{O}$ line but only the outer layers of the cloud in the ${ }^{12} \mathrm{C}^{16} \mathrm{O}$ line. It is possible, of course, that each of the stars is located near the edge of the cloud in the direction of the Sun and that the local excitation of the cloud by the star or a local increase in the CO density surrounding the star accounts for the peak in line intensity. This is not as unlikely as it may superficially seem. If the $\mathrm{CO}$ opacity in these clouds is high, the cloud will very likely have considerable optical extinction, and stars lying deep in the cloud or behind it could not be seen. We hesitate, however, to derive CO column densities and estimates of cloud densities and masses on the basis of the above assumptions without some further evidence that this geometry holds.

One could argue that the assumption of a terrestrial ${ }^{12} \mathrm{C} /{ }^{13} \mathrm{C}$ abundance ratio is the source of the problem, that really the ${ }^{12} \mathrm{C}^{16} \mathrm{O}$ line is optically thin, and that the line intensities reflect the interstellar isotopic abundances. On this basis, ${ }^{12} \mathrm{C} /{ }^{13} \mathrm{C}$ abundance ratios are obtained varying from 2 to 10 , values similar to those obtained for evolved giant K stars (Day 1973). However, observations of the ${ }^{12} \mathrm{C}^{18} \mathrm{O}$ line in other sources 

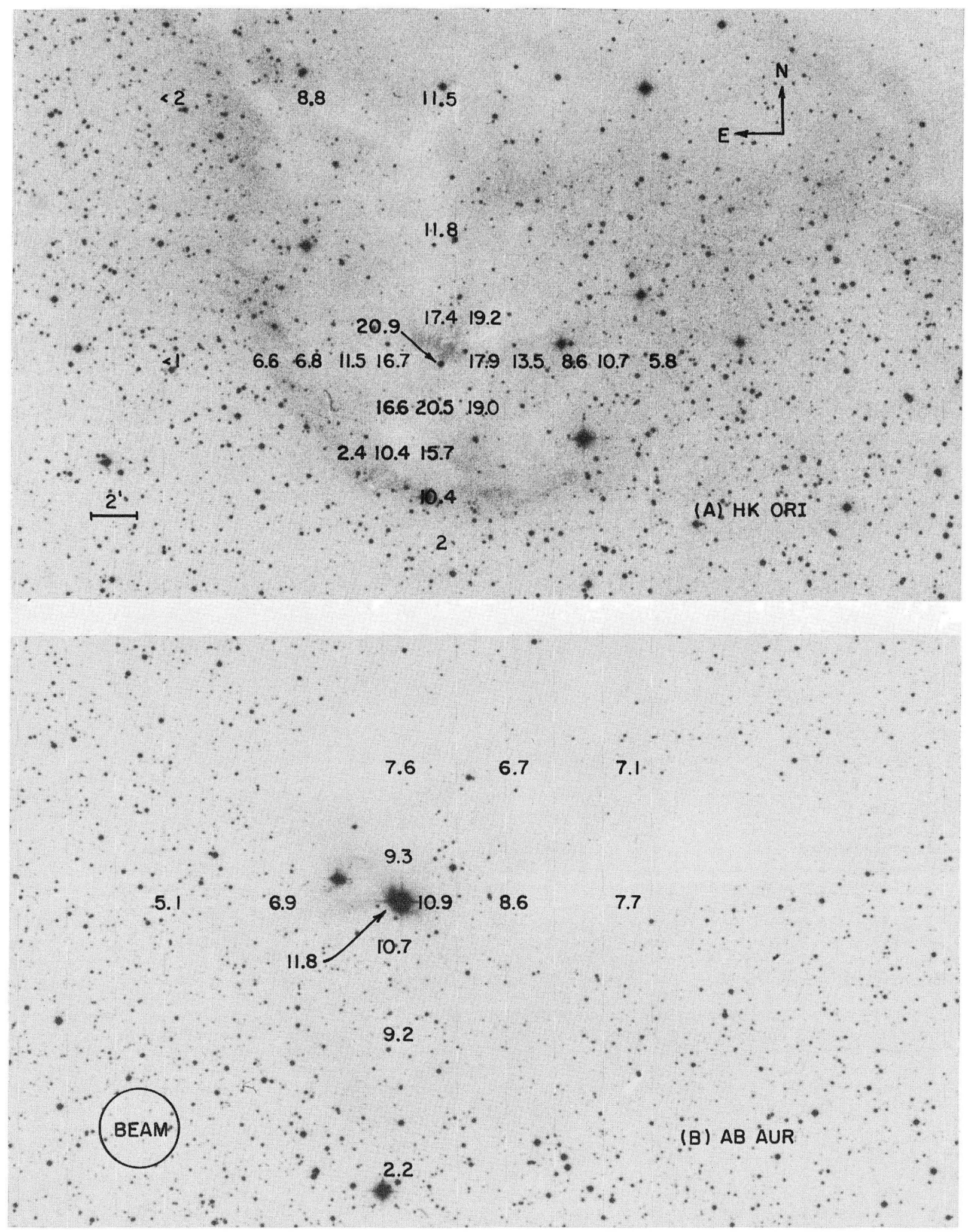

FIg. 1.-The region (A) surrounding the emission star HK Ori and the region (B) surrounding the emission star $\mathrm{AB}$ Aur with the peak line intensity $\left(\eta_{p} T_{B}\right)$ written at the positions where ${ }^{12} \mathrm{C}^{16} \mathrm{O}(J=1-0)$ emission was observed. Enlargements from the Palomar Sky Survey (red prints); the blue prints show reflection nebulosity close to the two emission stars.

LOREN et al. (see page L69). 
(Penzias et al. 1972) yield an approximately terrestrial abundance ratio $\left({ }^{12} \mathrm{C} /{ }^{13} \mathrm{C}\right) /$ $\left({ }^{16} \mathrm{O} /{ }^{18} \mathrm{O}\right)$. In the cloud in front of $\zeta$ Oph the ${ }^{12} \mathrm{C} /{ }^{13} \mathrm{C}$ ratio is known to be nearly terrestrial (Vanden Bout 1972). Finally, it is difficult to see how the ${ }^{12} \mathrm{C} /{ }^{13} \mathrm{C}$ ratio can vary over small distances within the same interstellar cloud, as our ${ }^{12} \mathrm{C}^{16} \mathrm{O}$ and ${ }^{13} \mathrm{C}^{16} \mathrm{O}$ intensity maps for these sources would indicate.

A third possible solution to this dilemma may lie in the structure of the clouds. If the antenna beam were not uniformly filled with a single cloud, but rather contained several small clouds and/or dense filamentary structures, then observations in either line would see deep into the cloud complex to the vicinity of the star, where the excitation of the line is stronger. Further mapping of these clouds and other young emission-line star regions, in the lines of $\mathrm{CO}$ and other molecules, is in progress in an effort to determine their structure.

This work was supported by NSF grant GP-36548 and a grant from the Research Corporation.

\section{REFERENCES}

Davis, J. H., and Vanden Bout, P. A. 1973, Ap. Letters, in press.

Day, R. W., Lambert, D. L., and Sneden, C. 1973, $A$ p. J., in press.

Herbig, G. 1960, Ap. J. Suppl., 6, 337.

Larson, G. 1969, M.N.R.A.S., 145, 271.

Liszt, H. 1973, private communication.

Penzias, A. A., Jefferts, K. B., Wilson, R. W., Liszt, H., and Solomon, P. M. 1972, Ap. J. (Letters), 178, L35.

Penzias, A. A., and Burrus, C. A. 1973, Ann. Rev. Astr. and Ap., 11, in press.

Solomon, P. 1973, Physics Today, 26, 32.

Strom, S. E., Strom, K. M., Yost, J., Carrasco, L., and Grasdalen, G. 1972, Ap. J., 173, 353.

Vanden Bout, P. A. 1972, Ap. J. (Letters), 176, L127.

Wilson, R. W., Jefferts, K. B., and Penzias, A. A. 1970, Ap. J. (Letters), 161, L41. 